\title{
ASSESSMENT OF ANTHROPOGENIC FACTOR OF ACCIDENT RISK ON THE MAIN OIL PIPELINE PASCUALES - CUENCA IN ECUADOR
}

\author{
Johnny Robinson Zambrano Carranza ${ }^{1}$, Stanislav Kovshov' ${ }^{2 *}$, Evgeniy Lyubin ${ }^{2}$ \\ ${ }^{1}$ Escuela Politécnica Nacional, Ecuador \\ ${ }^{2}$ Saint Petersburg Mining University, Russia
}

The pipeline infrastructure of Latin America countries, including the Republic of Ecuador, has a significant accident potential. Accidence rate is facilitated by the diversity of natural and climatic conditions in the region, military-political instability in its separate parts, and imperfection of the standards for the production of pipes and equipment. The technical condition of the pipeline systems operated in Latin America for $15-20$ years is imperfect. Depreciation or replacement of spent equipment and elements of the pipeline infrastructure is not being carried out at an adequate pace. Ecuador, for example, has a stable dynamics of increasing accidents at pipeline infrastructure facilities. Therefore, an assessment of the risk of the condition of the main pipelines should be carried out. Anthropogenic risk is one of the most important accident factors (50\% of all risk on main oil pipelines in Ecuador). To evaluate it, the methodology of Federal Safety Manual is proposed. The anthropogenic risk is calculated for 3 main sections of Pascuales - Cuenca pipeline, which supports with oil the provinces of Cañar, Loja, Zamora Chinchipe and Morona Santiago. For the foothill area, the specific probability of accidents is the most, and for the coastal and flat areas less and equals to 0.15 and 0.14 , respectively. The performed accident analysis will allow taking the necessary measuresto maintain the pipeline in working condition.

Key words: Pipeline, Risk assessment, Pascuales - Cuenca pipeline, Oils, Ecuador oil infrastructure, Anthropogenic risk factor.

\section{INTRODUCTION}

Accidents on pipelines are accompanied by significant losses of transported raw materials and large-scale pollution of the nature. Fuel spillages cause soil degradation [Kovshov et al., 2015]. To restore the contaminated soils, additional measures are needed, e.g. biogenic [Kovshov, 2013; Kovshov\&Kovshov, 2014]. Besides, highly aggressive mixtures are released during leakages into the environment causing significant damage [Pashkevich\&Antciferova, 2013]. All this creates a very negative effect on the nature of Ecuador, significantly affecting both the coastal plains and areas adjacent to the Andes, as well as the Ecuadorian part of the Amazon rainforest [Bravo, 2007].

There are several ways to assess the anthropogenic risk on oil pipelines: phenomenological, deterministic, expert and probabilistic [Vtorushina et al., 2017]. It is promising to use neural networks allowing to reveal hidden rules in chaotic systems, which include technogenic risks that appear in the gas transmission systems of JSC Gazprom [Podavalov, 2008]. To assess the quantitative risk of oil pipeline failure, the combination of subjective (which is analytic hierarchy process) and objective (which is entropy method) weighting methods can be used [Guo et al., 2016]. It was proposed to combine entropy weight method with grey clustering method, which can divide risk indexes in several groups according to whitenization weight function [Huetal., 2017]. It is noted the quantitative risk assessment technique is one of the most credible. Nevertheless, the adjustment of the method is required, due to lack of the necessary data. Thereby, the pipeline comprehensive risk analysis algorithm was suggested [Gharabagh et al., 2009]. Such risk factors as third-party damage index, corrosion index, design index, and incorrect operations index are considered in detail [Muhlbauer, 2004]. It is reported, third-party activities affect significantly at accidence rate on oil and gas pipelines in China. Pipeline fragility - overall reliability method was used for quantitative risk assessment. Proposed model helps to reduce costs and more accurately indicate the sections of the pipeline with high failure risk [Peng et al., 2016]. A fuzzy Bayesian belief network used for risk assessment in oil and gas pipelines showed that the most significant risk factors are construction defect, overload, mechanical damage, bad installation and quality of worker [Kabir et al., 2015]. Monte Carlo simulations for the probabilistic permanent fault displacement hazard were used to assess seismic risk on buried continuous pipelines [Cheng\&Akkar, 2017]. Neural networks - fuzzy logic model was used for assessment the risk of biofouling on pipeline. Dependences of biofouling risk from roughness and temperature, as well as, from water content and velocity were received [Urquidi-Macdonald et al., 2014]. Modern systems for diagnostics of oil pipelines technical condition do not always satisfy the requirements of the oil industry. It seems promising, to consider the principle of the pipeline diagnostics system using a constant pulsating magnetic field, instead of imperfect wave intratubal methods [Proskuryakov\&Dementev, 2016]. It is reported, third party activity is one of the factors with highest risk impact. 
Monte Carlo simulation and analytic network process model was used to test existing gas pipeline in Qatar and satisfactory results were received [El-Abbasy et al., 2015]. The factor of internal corrosion was assessed with Bayesian belief network approach. It was shown, internal corrosion depends on pipeline operating pressure and small diameter pipelines are the most vulnerable [Shabarchin\&Tesfamariam, 2016].

A list of the main causes of accidents on main pipelines in Russia is shown in Figure 1.

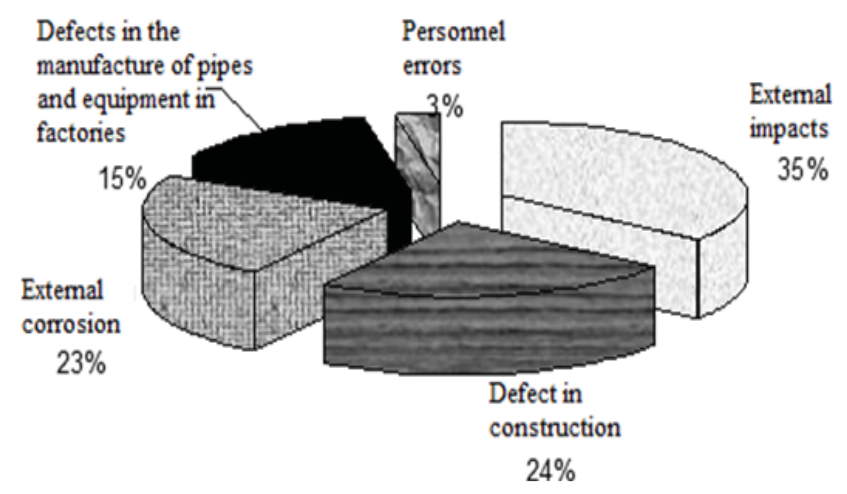

Figure 1: Distribution of accidents causes on the main pipelines of Russia

This assessment of the causes of accidents in the practice of industrial safety management systems in Russia formed the basis for the creation of various methods for assessing the risk of accidents on main pipelines.

For comparison, the data on spillage frequencies in Europe are given in Fig. 2.

The structure of the main causes of accidents in Ecuador differs quite significantly. The share of external anthropogenic impacts accounts for almost $50 \%$ of emergencies, the role of corrosion due to the lack of temperature and humidity jumps during the year is minimal. The factor of poor quality of pipes and conducting of construction works is about the same. Also in Ecuador, the role of the "human factor" in accidents is twice higher, which is explained by the lack of highly qualified engineering personnel serving engineering communications.

At the same time, the actual lack of own methods for assessing accident risk remains an important scientific and methodological problem of industrial safety in Ecuador.

\section{Methods}

As a methodological basis for assessing the anthropogenic component of the accident risk on main pipelines in Ecuador, the use of Federal Safety Manual for assessing the risk of accidents at main oil and oil products pipelines is proposed.

Emergency situations on main oil pipelines can be characterized by a certain variety in the specific frequency of accidents both the all over pipeline $\bar{\lambda}$ and also in its separate sections $\lambda_{n}$. This division is based on differences in constructive and technological characteristics; design, construction and operation features; external natural conditions, economic and political environment.

$$
\lambda_{n}=\bar{\lambda} \cdot k_{\text {inf }} \cdot k_{s} \cdot k_{l}
$$

where $k_{\text {inf }}$ - coefficient of influence; $k_{s}$ - coefficient of strength, defined as a value, inverse to the ratio of the actual stock of strength of investigated section of the main pipeline, to the coefficient of strength of all pipeline; $\mathrm{k}_{1}$ - coefficient considering the method of laying the pipeline. Coefficient considering the method of laying the pipeline. $k_{1}=0.1-$ on the sections made by microtun-

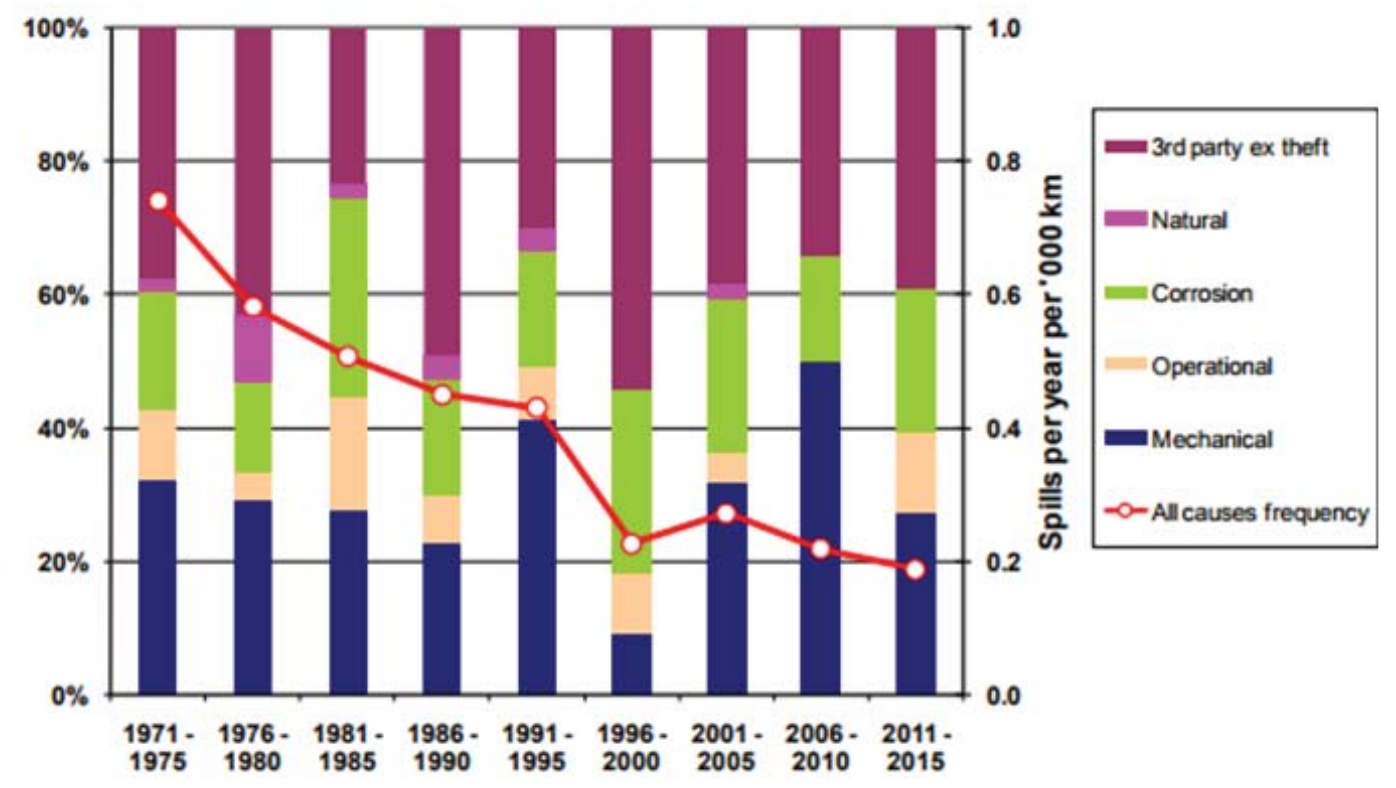

Figure 2: Cold pipelines spillage frequencies in Europe by cause (excluding theft) [Concawe report, 2017]. 
nelling technology; $k_{1}=0,4-$ on the sections made by directional drilling; $k_{-}=0,6-$ on the sections executed by the technology "pipe-in-pipe" or with the use of the pipes, coated with concrete; and $\mathrm{k}_{1}=1-$ on all other sections.

On each investigated section of the route, it is necessary to determine the value of the coefficient of influence $\mathrm{k}_{\text {inf }}$, showing how many times the specific frequency (probability) of accidents on the section differs from the average for this route. Coefficient of influence is determined using a standardized point evaluation system. For each value of the factor, with calculated or expert method, the number of points (on 10-point scale), expressing the degree of factor's influence, is determined. Scorings of each investigated factor are analyzed through the formula:

$$
k_{\text {inf }}=\frac{B_{n}}{B_{\text {aver }}}
$$

where $B_{n}$ is the point evaluation of the nth section of the main oil pipeline route, calculated as:

$$
B_{n}=\sum_{i=1}^{I} \sum_{j=1}^{J(i)} \rho_{i} \cdot q_{i j} \cdot B_{i j}
$$

$\mathrm{B}_{\text {aver }}$ - average point evaluation of the main oil pipeline route, defined as:

$$
B_{\text {aver }}=\frac{1}{N} \cdot \sum_{n=1}^{N} B_{n}
$$

where $\mathrm{N}$ is the total number of sections of the main pipeline considered.The value is determined on the basis of accident statistics in the organization operating the main oil pipeline. Also this parameter can be calculated by the formula:

$$
\bar{\lambda}=\lambda_{\text {aver }} \cdot \mathrm{k}_{\mathrm{D}} \cdot \mathrm{k}_{\mathrm{reg}}
$$

where $\lambda_{\text {aver }}$ - average accident rate at all main oil pipelines in the country for the last 5 years.

$k_{D}$ - diametrical coefficient, which is determined from the accident statistics, depending on the nominal diameter $\mathrm{DN}$ of the pipeline. The values are taken in accordance with Table 1.

Table 1. Values of the coefficient $k_{D}$ for different nominal diameters of main oil pipelines

\begin{tabular}{|c|c|c|c|c|c|c|c|}
\hline $\begin{array}{c}\mathrm{DN}, \\
\mathrm{mm}\end{array}$ & 1400 & 1200 & 1000 & 800 & 700 & 500 & $<500$ \\
\hline $\mathrm{k}_{\mathrm{D}}$ & 0.35 & 0.85 & 1.60 & 1.25 & 1.40 & 1.20 & 1.10 \\
\hline
\end{tabular}

$\mathrm{k}_{\text {reg }}$ - regional coefficient.

\section{Results and Discussion}

The pipeline project Pascuales - Cuenca develops in an approximate length of $205 \mathrm{~km}$ in the regions of Guayas, Azuay and Cañar (Figure 3).

The main pipeline starts in the coastal zone near the city of Guayaquil and ends with the Cuenca terminal, which stores the transported oil products, as well as liquefied petroleum gas. To maintain the required level of pressure in the pipeline, and to monitor its condition, three intermediate pumping stations are operated near the settlements of La Delicia, Ducur and Charcay.

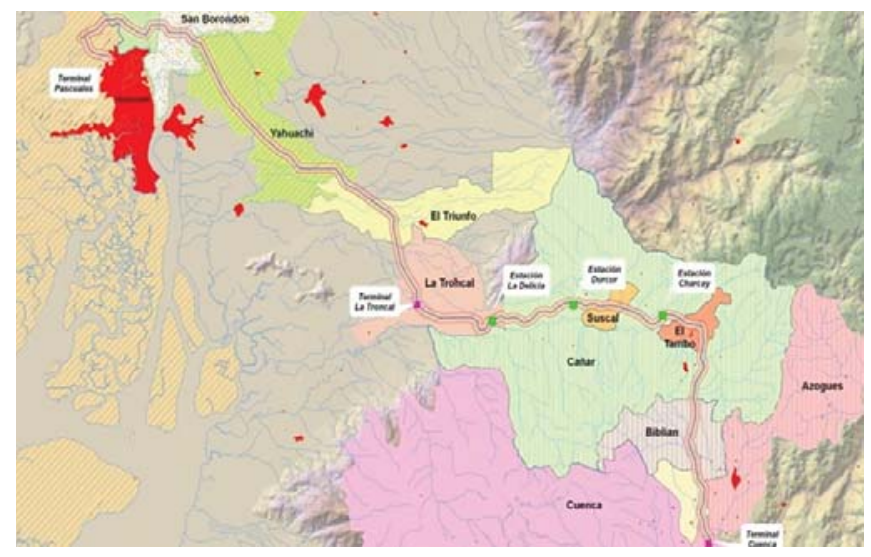

Figure 3: Location of the Pascuales - Cuenca main pipeline

The physico-geographical features of the zone of the main pipeline stretch and its relatively small area, make it possible to identify three sections, analyzed from the point of view of the accident risk: coastal, flat and foothill. In accordance with the proposed methodology, the point evaluation of each of the allocated sections of the main oil pipeline route has the following sequence of actions.

Based on the accident statistics on the main oil pipelines, five groups of influence factors are identified, indicating the relative "contribution" $\rho_{i}$ of each group (i from 1 to 5 ) in the total statistics of emergency failures using the weighting coefficient $\rho_{\mathrm{i}}$ (Table 2).

Table 2. Accident factors and their weighting coefficients

\begin{tabular}{|c|l|c|}
\hline \multicolumn{2}{|c|}{ Designation and name of a group of factors } & $\begin{array}{c}\text { Groupshare, } \\
\rho_{\mathrm{i}}\end{array}$ \\
\hline $\mathrm{Gr}_{1}$ & External anthropogenic impacts & 0.60 \\
\hline $\mathrm{Gr}_{2}$ & Corrosion factor & 0.05 \\
\hline $\mathrm{Gr}_{3}$ & Natural and climatic factor & 0.05 \\
\hline $\mathrm{Gr}_{4}$ & $\begin{array}{l}\text { Constructive and technological } \\
\text { factor }\end{array}$ & 0.10 \\
\hline $\mathrm{Gr}_{5}$ & Defects in pipe body and welds & 0.20 \\
\hline
\end{tabular}

Assessment of external anthropogenic impacts

As can be seen from Table 2, of the proposed factors, the accident rate on main oil pipelines is determined on $60 \%$ by external anthropogenic influences.

This group includes the factors external to the investigated main pipeline, shown in Table 3 , which affect the probability of damage from third party activity.

All over the length, the pipeline Pascuales-Cuenca has a certain specificity: in the coastal and flat areas, it 
mainly passes under the ground, in the foothills - passes either over the surface or above the ground. Herewith, constantly occurring water obstacles are always overcome by overhead way.

\section{Table 3: Factors of the group "External Anthropogenic} Impacts"

\begin{tabular}{|c|l|c|}
\hline \multicolumn{2}{|l|}{ Designation and name of influence factor } & $\begin{array}{c}\text { Share in a } \\
\text { group } \rho_{1 j}\end{array}$ \\
\hline$F_{11}$ & $\begin{array}{l}\text { Depth (in the ground) or height } \\
\text { (above the ground) of pipeline } \\
\text { laying }\end{array}$ & 0.4 \\
\hline$F_{12}$ & Level of anthropogenic activity & 0.2 \\
\hline$F_{13}$ & $\begin{array}{l}\text { The danger of sabotage and tie-in } \\
\text { with the aim of stealing oil and oil } \\
\text { product }\end{array}$ & 0.4 \\
\hline
\end{tabular}

Then, averaged, the scoring value for the actual depth (height) of the laying is calculated by the following formulas:

$B_{11}=1+25^{*}(h-0.6)^{2}=1+25^{*}(1-0.6)^{2}=5-$ for the foothill area (since $\mathrm{h}-$ the height of laying $=1 \mathrm{~m}$ );

$\mathrm{B}_{11}=0.83^{*}(1.8-\mathrm{h})=0.83^{*}(1.8-1.5)=0.25-$ for flat and coastal areas (mean laying depth $=1.5 \mathrm{~m}$ ).

The level of anthropogenic activity is estimated based on the sum of the factors $\mathrm{m}$, presented in Table 4.

All study areas are characterized by approximately the same population density, amounting to 55-60 people/ $\mathrm{km} 2$. Accordingly, the factor $m=3$. The activity of construction works at the sites is different: for the coastal and foothill areas it can be estimated as high $(=3)$, for the flat area - as moderate $(=2)$. All three districts are characterized by a small number of communications of other departmental affiliations $(=0.5)$ and the presence of road and rail sections $(=2)$.

Table 4: Level of anthropogenic activity

\begin{tabular}{|c|c|c|c|}
\hline $\mathrm{m}$ & \multicolumn{2}{|c|}{ Name of the component $\mathrm{m}$} & $\mathrm{B}_{12}{ }^{(\mathrm{m})}$ \\
\hline \multirow[t]{2}{*}{1} & \multirow{2}{*}{$\begin{array}{l}\text { The average } \\
\text { population density } \\
\mathrm{H}_{\text {pop }} \text { in a } 3-\mathrm{km} \text { strip } \\
\text { along the route }\end{array}$} & $\begin{array}{l}0<\mathrm{H}_{\text {pop }}<50 \text { people/ } \\
\mathrm{km}^{2}\end{array}$ & $0,06 * \mathrm{H}_{\text {pop }}$ \\
\hline & & $\mathrm{H}_{\mathrm{pop}}>50$ people/km² & 3 \\
\hline \multirow[t]{4}{*}{2} & \multirow{4}{*}{$\begin{array}{l}\text { Frequency of } \\
\text { construction and } \\
\text { other infrastructure } \\
\text { works carrying out }\end{array}$} & high & 3 \\
\hline & & moderate & 2 \\
\hline & & low & 1 \\
\hline & & absence & 0 \\
\hline \multirow[t]{3}{*}{3} & \multirow{3}{*}{$\begin{array}{l}\text { Presence of other } \\
\text { main pipelines and } \\
\text { communications }\end{array}$} & large quantity & 2 \\
\hline & & small quantity & 0.5 \\
\hline & & $\begin{array}{l}\text { absence of } \\
\text { extra-departmental } \\
\text { communications }\end{array}$ & 0 \\
\hline \multirow[t]{2}{*}{4} & \multirow{2}{*}{$\begin{array}{l}\text { Density of roads } \\
\text { and railways }\end{array}$} & Roads presence & 2 \\
\hline & & Roads absence & 0 \\
\hline
\end{tabular}

Thus, the coefficient $\mathrm{B}_{12}=3+3+0.5+2=8.5$, for the coastal and foothill areas, and $\mathrm{B}_{12}=3+2+0.5+2=7.5$, for the flat area.

B13 - point evaluation of the hazard factor of sabotage and tie-ins to the pipeline with the purpose of oil stealing for the conditions of Ecuador, can be determined using Table 5.

For all three sections, attempts to steal the oil were detected, but there were very few of them. Inspection of the pipeline route condition is carried out by air transport, there are no automated systems for detecting the tie-ins. Thus, for all three sections, this criterion can be estimated as $B_{13}=2$.

Table 5: Danger of sabotage and tie-ins

\begin{tabular}{|c|c|c|}
\hline \multicolumn{2}{|c|}{ Name of the component } & $\mathrm{B}_{13}{ }^{(\mathrm{m})}$ \\
\hline \multicolumn{2}{|c|}{$\begin{array}{l}\text { In the investigated area, attempts to steal oil were } \\
\text { not detected }\end{array}$} & 0 \\
\hline \multirow{3}{*}{$\begin{array}{l}\text { Attempts to steal } \\
\text { oil were detected } \\
\text { in the investigaed } \\
\text { area. In order to } \\
\text { prevent this, the } \\
\text { main pipeline route } \\
\text { is patrolled }\end{array}$} & $\begin{array}{l}\text { Air inspection of the route is } \\
\text { carried out from two to five } \\
\text { times a week }\end{array}$ & 2 \\
\hline & $\begin{array}{l}\text { Ground inspection of the } \\
\text { route with a frequency of } 2-3 \\
\text { times per week without air } \\
\text { inspection of the route }\end{array}$ & 5 \\
\hline & $\begin{array}{l}\text { Ground inspection of the } \\
\text { route with a frequency of } 1 \\
\text { time per week without air } \\
\text { inspection of the route }\end{array}$ & 8 \\
\hline \multicolumn{2}{|c|}{$\begin{array}{l}\text { The system of automated detection of tie-ins has } \\
\text { been installed }\end{array}$} & 0 \\
\hline \multicolumn{2}{|c|}{$\begin{array}{l}\text { In the investigated area, no measures of } \\
\text { protection were taken in the presence of the fact of } \\
\text { tie-ins or sabotages }\end{array}$} & 10 \\
\hline
\end{tabular}

Thus, it is possible to carry out a scoring of the factor "External anthropogenic impacts" for the three sections of the main oil pipeline:

- for the coastal area:

$B_{n}=0.6^{*}\left(0.4^{*} 0.25+0.2^{*} 8.5+0.4^{*} 2\right)=1.56$;

- for the flat area

$B_{n}=0.6^{*}\left(0.4^{*} 0.25+0.2 * 7.5+0.4 * 2\right)=1.44$;

- for the foothill area

$B_{n}=0.6 *\left(0.4 * 5+0.2 * 8.5+0.4^{*} 2\right)=2.7$.

The average score for the whole route of the Pascuales - Cuenca main pipeline is $B_{\text {aver }}=(1.56+1.44+2.7) / 3=1.9$.

Hence, the coefficient of influence of external anthropogenic impacts:

- for the coastal area $\mathrm{k}_{\mathrm{inf}}=1.56 / 1.9=0.82$;

- for the flat area $\mathrm{k}_{\mathrm{inf}}=1.44 / 1.9=0.76$;

- for the foothill area $\mathrm{k}_{\mathrm{inf}}=2.7 / 1.9=1.42$.

The average accident rate at the main oil pipelines in Ecuador over the past 5 years $\lambda_{\text {aver }}=0.13$ accidents per 
year per $1000 \mathrm{~km}$.

The nominal diameter DN of the Pascuales - Cuenca oil pipeline is $609 \mathrm{~mm}$, therefore the diametric coefficient can be taken equal to 1.4 .

The territory of Ecuador is rather small in area $283,360 \mathrm{~km}$, so in calculations the regional coefficient can be neglected and assigned a value of 1 .

Accordingly, the specific frequency (probability) of accidents over the entire pipeline $\bar{\lambda}=0.13^{*} 1.4^{*} 1=0.18$.

Unfortunately, there is no reliable information on the parameters of the actual stock of strength of the main pipeline in open sources. In the absence of data, the strength factorks is taken to be 1 .

The method of Pascuales-Cuenca oil pipeline laying cannot be unequivocally attributed to any of the variants proposed in the methodology, therefore, the coefficient considering the method of laying $k_{l}$, can be averaged taken equal to 1.

Thus, the specific frequency (probability) of accidents at certain sections of the Pascuales-Cuenca pipeline:

- for the coastal area $\lambda_{n}=0.18^{*} 0.82=0,15$;

- for the flat area $\lambda_{n}=0.18^{*} 0.76=0.14$;

- for the foothill area $\lambda_{n}=0.18 * 1.42=0.26$.

In the practice of results representation of the specific accident rate evaluation in certain sections of main pipelines, it is customary to use bar graphs. Thus, the final form of accident analysis for the Pascuales - Cuenca pipeline sections can be presented in Figure 4.

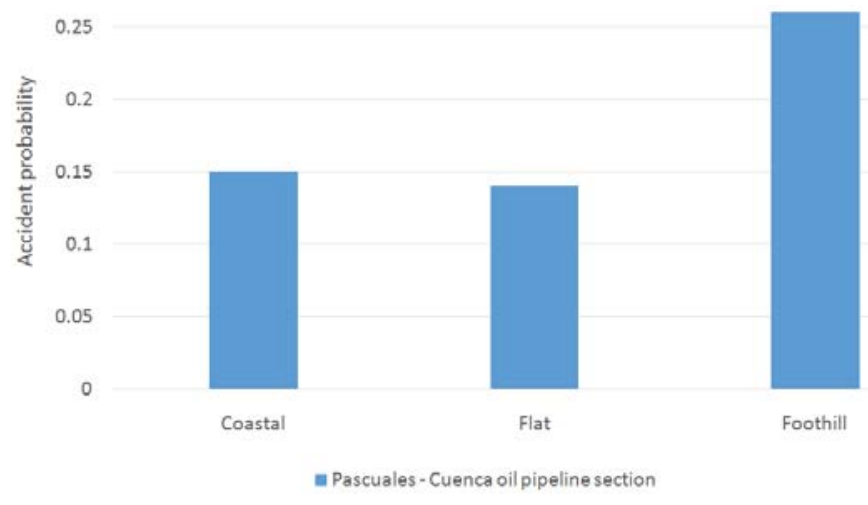

Figure 4: Estimation of the accidents caused by external anthropogenic impact on separate sections of the Pascuales - Cuenca oil pipeline.

\section{CONCLUSION}

Thus, according to the results of the study, the following conclusions can be drawn:

1. The share of the anthropogenic accident factor on the main pipelines in Ecuador accounts for more than $50 \%$ of the cases.

2. The physico-geographical features of the stretch area of the Pascuales - Cuenca main oil pipeline of Ecuador and its relatively short length allow to distinguish three sections analyzed from the point of view of the accident risk: coastal, flat and foothill.

3. In accordance with Federal Safety Manual, the analysis and calculation of the main accident rates have been carried out, both along the entire Pascuales Cuenca pipeline, and on its separate sections.

4. It has been established that the greatest accident potential caused by external anthropogenic impact is typical for the foothill area, which is primarily is connected with the overground pipeline laying factor in view of complexity of district areography.

\section{ACKNOWLEDGMENTS}

The article was prepared with the grant support of the Academic Council of the Mining University on the basis of the results of the internship and scientific work at the National Polytechnic School of Ecuador.

\section{REFERENCES}

Bravo, E. (2007). Los impactos de la explotación petrolera eneco sistemas tropicales y la biodiversidad. Acciónecológica, Vol. 24 (1), P. 35-42.

Cheng, Y., \&Akkar, S. (2017). Probabilistic permanent fault displacement hazard via Monte Carlo simulation and its consideration for the probabilistic risk assessment of buried continuous steel pipelines. Earthquake Engineering \& Structural Dynamics, 46(4), 605-620.

El-Abbasy, M. S., Senouci, A., Zayed, T., \&Mosleh, F. (2015). A condition assessment model for oil and gas pipelines using integrated simulation and analytic network process. Structure and Infrastructure Engineering, 11(3), 263-281.

Gharabagh, M. J., Asilian, H., Mortasavi, S. B., Mogaddam, A. Z., Hajizadeh, E., \&Khavanin, A. (2009). Comprehensive risk assessment and management of petrochemical feed and product transportation pipelines. Journal of Loss Prevention in the Process Industries, 22(4), 533-539.

Guo Y., Meng X., Wang D., Meng T., Liu S., He R. (2016). Comprehensive risk evaluation of long-distance oil and gas transportation pipelinesusing a fuzzy Petri net model. Journal of Natural Gas Science \& Engineering, Vol. 33, P. 18 - 29, doi: 10.1016/j.jngse.2016.04.052.

Hu, Y., Liu, K., Xu, D., Zhai, Z., \& Liu, H. (2017, August). Risk Assessment of Long Distance Oil and Gas Pipeline Based on Grey Clustering. In Big Knowledge (ICBK), 2017 IEEE International Conference on (pp. 198-201). IEEE.

Kabir, G., Sadiq, R., \&Tesfamariam, S. (2015). A fuzzy Bayesian belief network for safety assessment of oil and gas pipelines. Structure and Infrastructure Engineering, 12(8), 874-889.

Kovshov, S. (2013). Biological ground recultivation and increase of soil fertility. International Journal of Ecology \& Development, 25(2), 105-113. 
Kovshov, S. V., Garkushev, A. U., \&Sazykin, A. M. (2015). Biogenic technology for recultivation of lands contaminated due to rocket propellant spillage. ActaAstronautica, 109, 203-207.

Kovshov, S. V., \&Kovshov, V. P. (2014). Biogenic fixation of dusting surfaces. Life Science Journal, 11 (9), 401 404.

Muhlbauer, W. K. (2004). Pipeline risk management manual: ideas, techniques, and resources. Elsevier.

Pashkevich M.A., Antciferova T.A. (2013). Risk assessment of anthropogenic impact of the fueland energy complex. Journal of Mining Institute, Vol. 203, P. 225 - 228.

Peng, X. Y., Yao, D. C., Liang, G. C., Yu, J. S., \& He, S. (2016). Overall reliability analysis on oil/gas pipeline under typical third-party actions based on fragility theory. Journal of Natural Gas Science and Engineering, 34, 993-1003.

Performance of European cross-country oil pipelines. Statistical summary of reported spillages in 2015 and since 1971. Concawe, Brussels, 2017.
Podavalov,I.Yu. (2008). Analysis of methods of technogenic risk calculation in the operation of main gas pipelines. Journal of Mining Institute, Vol. 178, P. 82 - 85.

Proskuryakov, R.M., Dementev A.S (2016). The building a system of diagnosing the technical condition of the pipeline on the basis of continuous pulsed magnetic field. Journal of Mining Institute, Vol. 218, P. $215-219$.

Shabarchin, O., \&Tesfamariam, S. (2016). Internal corrosion hazard assessment of oil \& gas pipelines using Bayesian belief network model. Journal of Loss Prevention in the Process Industries, 40, 479-495.

Urquidi-Macdonald, M., Tewari, A., \& Ayala H, L. F. (2014). A neuro-fuzzy knowledge-based model for the risk assessment of microbiologically influenced corrosion in crude oil pipelines. Corrosion, 70(11), 1157-1166. Vtorushina, A.N., Anishchenko, Y.V., Nikonova, E.D. (2017). Risk assessment of oil pipeline accidents in special climatic conditions. IOP Conf. Ser.: Earth Environ. Sci. 66012006. 